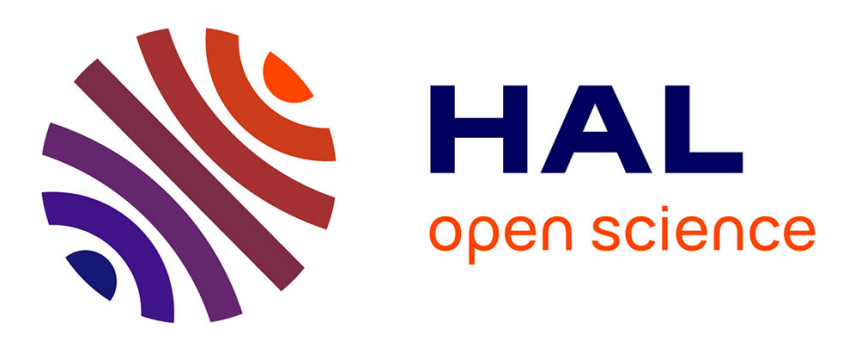

\title{
Emotional specificities of autobiographical memory after breast cancer diagnosis
}

Nastassja Morel, Jacques Dayan, Pascale Piolino, Armelle Viard, Djellila Allouache, Sabine Noal, Christelle Levy, Florence Joly, Francis Eustache, Bénédicte Giffard

\section{To cite this version:}

Nastassja Morel, Jacques Dayan, Pascale Piolino, Armelle Viard, Djellila Allouache, et al.. Emotional specificities of autobiographical memory after breast cancer diagnosis. Consciousness and Cognition, 2015, 35, pp.42-52. 10.1016/j.concog.2015.04.016 . inserm-01226417

\section{HAL Id: inserm-01226417 https://www.hal.inserm.fr/inserm-01226417}

Submitted on 9 Nov 2015

HAL is a multi-disciplinary open access archive for the deposit and dissemination of scientific research documents, whether they are published or not. The documents may come from teaching and research institutions in France or abroad, or from public or private research centers.
L'archive ouverte pluridisciplinaire HAL, est destinée au dépôt et à la diffusion de documents scientifiques de niveau recherche, publiés ou non, émanant des établissements d'enseignement et de recherche français ou étrangers, des laboratoires publics ou privés. 
3 Nastassja Morel ${ }^{1,2,3,4}$, Jacques Dayan ${ }^{1,2,3,4,5}$, Pascale Piolino ${ }^{6,7}$, Armelle Viard ${ }^{1,2,3,4}$, Djellila

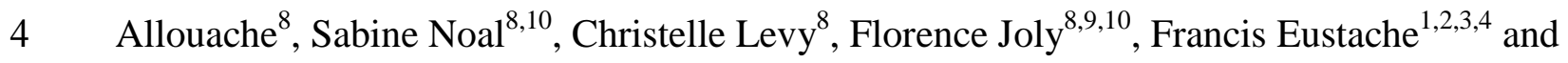
Bénédicte Giffard ${ }^{1,2,3,4}$

$6 \quad{ }^{1}$ U1077, INSERM, Caen, France

$7 \quad{ }^{2}$ U1077, University of Caen Lower Normandy, Caen, France

$8 \quad{ }^{3}$ U1077, Ecole Pratique des Hautes Etudes, Caen, France

$9 \quad{ }^{4}$ U1077, Caen University Hospital, Caen, France

$10{ }^{5}$ Department of Child and Adolescent Psychiatry, Guillaume Régnier University Hospital,

11 Rennes, France

${ }^{6}$ University of Paris Descartes, Sorbonne Paris Cité, Psychology Institute, Memory and 13 Cognition Lab, Boulogne Billancourt, France

$14{ }^{7}$ INSERM U894, Psychiatry and Neuroscience Centre, University of Paris Descartes, Paris, 15 France

$16{ }^{8}$ Department of Medical Oncology, François Baclesse Centre, Caen, France

$17{ }^{9}$ Caen University Hospital, Caen, France

1810 “Cancers and Preventions” joint team (INSERM, U1086), Caen, France

20 Corresponding author: Bénédicte Giffard

21 Université de Caen Basse-Normandie, Esplanade de la Paix, U.F.R. de Psychologie, 14032

22 Caen Cedex, France

23 E-mail: benedicte.giffard@unicaen.fr

24 Tel.: +33(0)2 31566279

25 Fax: +33 (0)2 31566693 
Cancer involves stressful events. One aspect of cognition that is impacted by stress is episodic autobiographical memory (EAM). EAM is intimately linked to self-representation. Some studies have revealed impairment of EAM in patients with breast cancer in remission. Yet, these studies failed to differentiate between the influence of adjuvant treatments and that of psychosocial factors. We therefore assessed the psychological impact of breast cancer diagnosis on EAM and self-representation profiles prior to any adjuvant treatment. Patients newly diagnosed with breast cancer $(n=31)$ and women without any history of cancer $(n=49)$ were compared on state anxiety, EAM and its emotional characteristics, and selfrepresentations. The most anxious patients retrieved fewer emotional details for memories than the controls, and had lower self-representation scores than the least anxious patients, who had no deficits in emotional detail retrieval. Our results revealed distinct EAM profiles for patients, reflecting two contrasting modes of coping with breast cancer.

Keywords: breast cancer, period of diagnosis, state anxiety, autobiographical memory, selfrepresentations 


\section{INTRODUCTION}

A growing body of research focuses on cognitive functioning in non-central nervous system (non-CNS) cancers, mainly in breast cancer. Complaints concern memory, attention or concentration problems which are mostly quite subtle, although they strongly affect patients' quality of life. Studies report cognitive deficits during and after completing adjuvant chemotherapy, often referred to as chemobrain (Wefel \& Schagen, 2012), but many of the recent prospective studies report performances below normal scores evenbefore adjuvant treatment has begun (Ahles et al. 2008; Quesnel et al. 2009; Cimprich et al. 2010; Wefel et al. 2010). These results suggest that, in addition to the aggressive effects of chemotherapy, combinations of biological and medical factors, such as side-effects of surgery and anesthesia, could also play a role in patients' cognitive impairment (Joly et al. 2011). Furthermore, due to the diagnosis of a life-threatening illness, cancer involves many stressful events that may lead to psychosocial changes (state anxiety and self-representations), and in some cases, to psychiatric symptoms, such as those reported in post-traumatic stress disorder (PTSD) or in major depression.

Such psychological distress may have adverse effects on cognition, and one aspect of cognition that is particularly vulnerable to stress-related symptoms is autobiographical memory (e.g. St Jacques et al. 2013). Autobiographical memory refers to personally relevant events extended over time and is important for grounding and modifying personal identity as it enables one to construct a sense of identity and continuity over time (Conway \& PleydellPearce, 2000). A bidirectional relationship exists between autobiographical memory and selfrepresentations: while autobiographical memory plays a fundamental role in the formation of self-representations, inversely, retrieval of the past is influenced by the current self, known as the working self (i.e., one's current beliefs, goals and self-images; Conway, 2005; Klein \& Lax, 2010). The Self-Memory System (SMS, Conway \& Pleydell-Pearce, 2000) emphasizes 
this interrelationship between self and memory. Autobiographical representations are organized hierarchically along three levels: from lifetime periods (extended over long periods of time), to generic events (repeated or extended in time), and lastly event-specific knowledge (contains specific episodic memories). This last level refers to episodic autobiographical memory (EAM) which supports our capacity to re-experience personal past events (i.e., to mentally travel in time) with their specific details, such as the spatiotemporal context, factual and emotional descriptions (Tulving, 2002; Piolino et al. 2009) (e.g., "I remember the moment when Mr O. asked me to sit at his desk to look at my tests. I felt anxious when he said he had the results. It was in December."). The SMS proposes an explanation concerning the voluntary retrieval of EAM when assessed using a semi-structured interview such as the Autobiographical Memory Task (AMT, Williams \& Broadbent, 1986) or the TEMPau task (for Test Episodique de la Mémoire du Passé autobiographique; Piolino et al. 2003). Generative retrieval provides controlled access to event-specific knowledge via the personal semantic knowledge base (lifetime periods and generic events). This generative retrieval process relies on both executive functions and the working self, which acts as a moderator between the demands of correspondence (memory should correspond to experience and reality) and coherence (memory should be consistent with one's current goals, self-images and beliefs) in the formation of memories (Conway et al. 2004).

Numerous studies have focused on autobiographical memory functioning in stress-related disorders. When asked to retrieve a specific episodic life event, depressed or traumatized patients with PTSD or acute stress disorder (ASD) instead tend to recall broader, repeated and generic events with no specific details, i.e. overgeneral memories (see Moore \& Zoellner, 2007; Sumner et al. 2010; Williams et al. 2007 for reviews). Based on the SMS, overgenerality occurs when the generative retrieval search process is aborted prematurely, before reaching the level of event specific knowledge (e.g., Haque et al. 2014). This 
phenomenon may rely on the interaction between executive dysfunction (deficits in executive resources limit the ability to conduct a successful retrieval search) and the current self. According to the CaR-FA-X model (capture and rumination, functional avoidance, and impaired executive control) proposed by Williams et al. (2007), overgeneral memories and avoidance of intrusive memories contribute to protect the self against specific stressful memories by decreasing the likelihood of any episodic recollection, as a means of affect regulation. The model also postulates that overgeneral memories occur when the generative retrieval search process is aborted as a result of two other mechanisms: capture and rumination (capture at a general autobiographical level which occurs particularly in individuals prone to rumination) and impaired executive control (e.g. inhibition and working memory capacity) which play a role in the strategic retrieval of a specific memory (see Sumner, 2012).

Deeber et al. (2012) suggest that the functional avoidance hypothesis might not only be proposed to explain overgeneral memories in depressed and traumatized patients, but also for healthy individuals, i.e. without psychiatric disorders. The authors observed that confronting healthy subjects with an acute stressor increases memory overgenerality, although this observation depends on the individual's general tendency to engage in (cognitive) avoidant coping. Thus, overgenerality could be a form of cognitive avoidance strategy used in a flexible way by nonclinical individuals only under certain conditions (Hermans et al. 2008). These studies suggest that reduced memory specificity for certain unpleasant events may be a natural and healthy coping strategy in individuals without psychiatric diagnoses. Indeed, autobiographical memory dysfunction - specifically overgenerality - has also been reported in specific medical populations (e.g., tinnitus patients, Andersson et al. 2013), patients with chronic pain (Liu et al. 2014), or in life-threatening illnesses such as patients with HIV (e.g., Abdollahi et al. 2012), but some of these patient groups were associated with psychiatric 
disorders like depression or PTSD.

121 In non-CNS cancer, a life-threatening illness in which psychological turmoil may occur, autobiographical memory impairment has also been observed (see Giffard et al. 2013, for a detailed review). In early studies, autobiographical memory overgenerality observed in

124 groups of patients with different types of cancer (breast, gastro-intestinal, lung, etc.) was also

125 found to be related to major depression or PTSD (Brewin et al. 1998; Kangas et al. 2005).

126 However, in comparison studies with healthy controls without any history of cancer, autobiographical memory overgenerality has also been observed in breast cancer patients who are in remission and have no stress-related psychiatric disorders (Nilsson-Ihrfelt et al. 2004; Bergouignan et al. 2011). In these two studies, patients were assessed several months after the end of adjuvant treatment (i.e., these patients had undergone surgery, chemotherapy and

131 radiotherapy, and sometimes hormonal therapy, too). Thus, no clear distinction can be drawn between the influence of aggressive adjuvant treatments and the impact of breast cancer diagnosis and its attendant psychosocial (state anxiety and self-representations) factors. The

134 diagnosis of this life-threatening illness exposes women to the cumulative effects of short135 and long-term stressful life events such as subsequent surgery associated with pain and 136 modified body image, accepting the possibility of death, uncertainty about the future, and awaiting consecutive adjuvant treatment such as chemotherapy (Pucheu, 2004; Carver et al.

138 2005; Caron et al. 2007; Baize et al. 2008; McGregor \& Antoni, 2009). A poor body image

139 resulting from cancer treatments has been shown to be associated with psychological distress

140 (Przezdziecki et al. 2013), and may lead to dissatisfaction with oneself (Stokes \& Frederick-

141 Recascino, 2003). The many different stages in this life-threatening illness may trigger or 142 heighten state anxiety and modify self-representations.

143 No study to date has investigated the relationship between state anxiety, EAM and modified 144 self-representations after a diagnosis of breast cancer and subsequent surgery, but before 
145 adjuvant treatments. Yet, it is crucial to understand the impact of the cancer diagnosis period

146 on these factors, and the adaptive processes these patients adopt to cope with this life-

147 threatening illness.

148 The objective of the present study was to assess the psychological impact of cancer diagnosis

149 on EAM retrieval, measured with a semi-structured interview, and on self-representations. To

150 this end, we compared patients with breast cancer who were yet to undergo adjuvant treatment

151 and healthy controls, assessing the main psychological variables that might interfere with

152 EAM, specifically state anxiety.

\section{2. METHODS}

\section{$155 \quad$ 2.1 Participants and Procedure}

156 Thirty-one women who had been newly diagnosed with breast cancer took part in this study.

157 Patient inclusion criteria were: (i) at least 45 years old; (ii) no metastatic breast cancer; (iii)

158 after surgery (tumorectomy or mastectomy) but before chemotherapy (5 Fluorouracil, 159 Epirubicin, Cyclophosphamide and Docetaxel) and, if necessary, radiotherapy and/or

160 hormonal therapy; (iv) no major psychiatric disorder before or during breast cancer diagnosis,

161 according to the criteria of the DSM-IV (Mini-International Neuropsychiatric Interview), and

162 absence of depressive state, as measured with the abridged version of the Beck Depression

163 Inventory (BDI; Beck et al. 1961); (v) no neurological disease; (vi) no drug use or alcohol

164 abuse; and (vii) no global cognitive impairment according to the criteria of the Mini Mental

165 Status Examination (Kalafat et al. 2003). Seventy-one patients were preselected on these

166 criteria at the medical oncology department of the François Baclesse Centre in Caen (France).

167 Subsequently, participants were contacted to schedule an appointment for our longitudinal

168 study with cognitive, EAM and psychosocial assessments, as well as MRI scanning sessions

169 (data not provided in this study) before and after chemotherapy treatment. Of the 71 patients 
170 eligible for the study, 22 patients declined their participation for several reasons: fear of the

171 MRI scanning sessions, length of the longitudinal study, or lack of interest. Ten patients could

172 not participate because time was too short prior to chemotherapy to conduct all assessments

173 (professional commitments or MRI scanner availability). The reason was not known for eight

174 patients. Finally, 31 patients participated in this study (44\% agreement rate). All of them

175 provided written informed consent to the study, which was conducted in accordance with the

176 Declaration of Helsinki and approved by the local ethics committee.

177 The control group consisted of 49 healthy women. Inclusion criteria were the same for

178 controls as they were for patients, with the additional criterion of no cancer history past or

179 present.

180 All participants were fluent in French. Anxiety, cognitive, EAM, and self-representation

181 assessments (detailed below) were administered in a quiet room, in the same conditions for

182 both patients and controls. The assessments were proposed over two sessions lasting $1 \mathrm{~h} 30$

183 each.

\section{$184 \quad 2.2$ Anxiety assessment}

185 Two questionnaires assessed the presence of anxiety on the basis of the State-Trait Anxiety

186 Inventory (STAI; Spielberger et al. 1970). State anxiety is a measure of situational anxiety,

187 with participants being asked to respond based on "how you feel right now" (corresponding to

188 the period of breast cancer announcement for our patients). Trait anxiety is a measure of a

189 general tendency to be anxious, with participants being asked to respond based on "how you

190 generally feel". Each subscale consists of 20 items scored on a four-point Likert-like scale.

191 Subscale scores range from 20 to 80, with higher scores indicating greater anxiety.

$192 \quad 2.3$ Cognitive assessment

193 Neuropsychological tests were administered to all participants to assess their cognitive

194 abilities: two tests of verbal and visual episodic memory processes that had previously been 
developed in our laboratory, based on the Encoding, Storage, Retrieval (ESR) paradigm

196 (Eustache et al. 1998; Chételat et al. 2003; Fouquet et al. 2012), the Digit Span Backward,

197 Letter-Number Sequencing and Arithmetic subtests of the Wechsler Adult Intelligence Scale

198 (WAIS; Wechsler 2008), the Trail Making Test (TMT) Parts A and B (Reitan, 1992), formal

199 and semantic verbal fluency (Cardebat et al. 1990), and the d2 Test of Attention

200 (Brickenkamp \& Zillmer, 1998).

201 To obtain more robust proxies of cognitive abilities and minimize the issue of multiple

202 statistical testing, six composite cognitive scores were computed, based on a procedure

203 described elsewhere (La Joie et al. 2014). Performances were Z-transformed and combined

204 (before averaging, $z$ scores derived from reaction times and errors were reversed so that

205 increasing values always indicated better performances). The episodic memory encoding and

206 retrieval scores were derived from two tests assessing verbal and visual processes, the first

207 one featuring a list of 16 words (verbal episodic memory), the second a list of eight

208 nonfigurative graphic signs (visual episodic memory). We used recognition performances for

209 verbal and visual items that had been superficially and incidentally encoded as a proxy for

210 encoding abilities (Encoding episodic memory task), and free recall performances for verbal

211 and visual items that had been deeply and intentionally encoded as a proxy for retrieval

212 abilities (Retrieval episodic memory task). The total scores on the Digit Span Backward, total

213 score in Letter-Number Sequencing and Arithmetic subtests were summed to form a working

214 memory score. Similarly, we combined performances on the TMT (time difference between

215 Parts B and A, and Part B perseverative errors) and formal and semantic verbal fluency

216 (number of words beginning with " $\mathrm{p}$ " and number of words in the "animals" category

217 produced in $2 \mathrm{~min}$ ) to form an executive function score. We summed the time taken to

218 perform the TMT Part A and the total number of items crossed out within the time limit in the

219 d2 Test of Attention to obtain a processing speed score. Finally, attentional errors in Parts A 
and B of the TMT and errors (where participants crossed out a d without two dashes or failed

221 to cross out a d with two dashes) in the $\mathrm{d} 2$ Test of Attention were combined to form an attentional error score.

\subsection{EAM assessment}

The EAM assessment took the form of a semi-structured interview developed and validated by Piolino et al. (2002, 2007, 2009): the Test Episodique de Mémoire du Passé autobiographique (TEMPau) test. The TEMPau consists in asking participants to retrieve one specific, detailed event situated in time and space for each of a number of different lifetime periods. Unlike the Autobiographical Memory Test (AMT, Williams \& Broadbent (1986)), the TEMPau is not time limited. Patients had to retrieve one event from each of following three lifetime periods: 18 -30 years old (reminiscence bump period), the last 2 years except for the last 6 months (before cancer period) and the last 6 months (cancer period). To compare them with the control group, patients were instructed to retrieve an event that was not related to cancer from the cancer period. We gave participants a very precise definition of a specific EAM, that is, a unique event lasting less than a day, located precisely in time and space, which can be recalled with factual (people, dialogues and anecdotes) and emotional (feelings, sensations, perceptions) details. In order to collect spontaneous memories only, no cue-word was given to retrieve memories from the different lifetime periods.

238 Each lifetime period recollection was audiotaped and transcribed verbatim. For each memory 239 with at least characteristics of uniqueness and short duration $(<24 \mathrm{~h})$, we then scored the 240 factual, spatial, temporal and emotional specific details, attributing one point to each detail 241 that was retrieved. Two independent raters assessed the specific details of each event provided 242 by participants. There was an interrater agreement rate of $72 \%(\kappa=0.61, p<0.001)$. Every 243 conflicting result was re-examined until a consensus was reached.

244 We calculated the following EAM scores: 
- Three overall scores, one for each lifetime period (/4): we summed the scores for specific details (factual, spatial, temporal and emotional) for each lifetime period (reminiscence bump, before cancer and cancer);

- Four specific detail scores (/3): we summed the scores for each type of specific detail (factual, spatial, temporal and emotional) across the three lifetime periods (reminiscence bump, before cancer and cancer).

Immediately after an event had been retrieved, we asked participants to rate the emotional characteristics of their recollection on two Likert-like scales:

- Emotional valence scale ranging from 0 (Unpleasant event) to 5 (Pleasant event);

- Emotional intensity scale ranging from 0 (Low intensity) to 5 (High intensity).

255 For both assessments, patients rated the emotions they had experienced when the event 256 originally took place (i.e., at encoding) and the emotions they experienced when they related 257 that event to the experimenter (i.e., at retrieval).

\subsection{Self-representation assessment}

Self-representations were assessed with the Questionnaire of Self-Representations (QSR)

260 (Duval et al. 2012). This questionnaire incorporates some of the main and recurrent items of 261 several commonly used self-concept scales, such as the Tennessee Self-Concept Scale 2 262 (TSCS2; Fitts \& Warren, 1996), the Revised Self-Consciousness Scale (RSCS; Scheier \& 263 Carver, 1985) and the Self-Concept Clarity Scale (SCCS; Campbell et al. 1996). Participants 264 have to rate 50 positive or negative descriptive statements (e.g., "I am an honest person", "I 265 do not feel at ease with other people") for self-descriptiveness on a 4-point Likert-like scale 266 ranging from 1 to 4 (1: Does not describe me at all; 2: Describes me a little; 3: Describes me 267 well; 4: Describes me absolutely). Each statement belongs to a particular category of self268 representation (e.g., physical, moral-ethical, personal, family, social, cognitive and 269 emotional). 
270 First, QSR internal validity was controlled for each participant. Validity scores allowed us to

271 take into account response biases, such as response conflict (difference between responses to

272 affirmative or negative statements), response incoherence (wide discrepancy between

273 responses to pairs of items with similar content) and social desirability (giving a favourable

274 impression). The first two biases were calculated on the basis of the 50 QSR items, and the

275 latter using the validated lie subscale of Coopersmith's Self-Esteem Inventory (Coopersmith,

276 1984). Next, we focused on two main scores: certainty and valence. We postulated that these

277 scores might change following the breast cancer announcement, owing to negative stressful

278 events and disruption of the daily routine. The certainty of self-concept score is an index of

279 the stability of self-knowledge trait, as reflected in the number of definite responses. Ratings

280 of 1 (Does not describe me at all) and 4 (Describes me absolutely) correspond to clear-cut and

281 consistent self-representations. Ratings of 2 (Describes me a little) and 3 (Describes me well)

282 are regarded as vague responses. The higher the certainty score, the more certain the self-

283 representation is. Finally, we calculated a valence score that measures self-esteem. The higher

284 the valence score, the more positive the self-representation is. The certainty and valence

285 scores are both calculated on the basis of the 50 statements and converted into percentages

286 (taking all categories of self-representation together).

$287 \quad 2.6$ Statistical Analyses

288 All the statistical analyses were performed with STATISTICA software (StatSoft, 2011). The 289 weakest significance threshold was set at $p=0.05$. Pearson's chi-squared tests (goodness of 290 fit) were conducted to assess the repartition of patients for clinical characteristics. We ran 291 Student's $t$ tests to compare the two groups of participants on their demographic, 292 psychological and composite cognitive scores.

293 To specify the effects of disease and state anxiety on autobiographical memory and self294 representations, participants were divided in two subgroups, based on the median state anxiety 
scores for each group (patients' median $=32$ : the least anxious patients, $n=16$, the most

296 anxious patients, $n=15$; controls' median $=26$ : the least anxious controls, $n=25$, the most anxious controls, $n=24$ ). A dispersion graph with the participants' state anxiety scores is presented in Figure 1. We conducted factorial analyses of variance (ANOVA) with the factors Group (patients, controls) and Anxiety (least anxious, most anxious) on the TEMPau scores

300 (overall scores per period, specific detail scores, and emotional intensity and valence scores) 301 and on the QSR scores (certainty and valence). These ANOVAs were followed by post-hoc comparisons using Fisher's Least Significant Difference (LSD) tests to compare group means. Relationships between variables were assessed using Spearman rank correlations.

\section{RESULTS}

3.1 Clinical characteristics, demographic and psychological data, and general cognitive assessments

Concerning clinical characteristics of the patient group, 22 women had undergone a tumorectomy and nine women a mastectomy (none of them had had a reconstruction

310 procedure before receiving the adjuvant treatment). Seven patients had been diagnosed with 311 Stage I breast cancer, while 12 patients had been diagnosed with Stage II and 12 with Stage 312 III. Patients included in this study were younger than those who were excluded (53 \pm 5 vs. 58 $313 \pm 9$ years old, $p=0.02)$, but there was no difference in either education level $(12 \pm 3$ vs. 11.9 $314 \pm 3.2$ years of education, $p=0.8$ ) or disease severity ( 7 vs. 10 patients with Stage I breast 315 cancer, 13 vs. 16 patients with Stage II, and 11 vs. 14 with Stage III; $p=0.9\left(\chi^{2}\right.$ test $)$ ).

316 The clinical characteristics of the patients enrolled in the study, and demographic, 317 psychological and general cognitive scores of the patients and controls are summarized in 318 Table 1. No significant differences were observed between the patients and controls for age $(p$ $319=0.71)$ or education level $(p=0.34)$. Concerning state anxiety, analyses revealed a significant 
difference between patients and controls $(p=0.01)$, with patients newly diagnosed for breast

321 cancer scoring higher than controls. No significant difference was found between the groups

322 on either trait-anxiety or BDI scores. Analyses of the cognitive assessment revealed

323 significantly poorer performances in patients compared with controls on episodic memory

324 retrieval $(p=0.048)$ and attentional scores $(p=0.009)$.

$325 \quad 3.2$ Episodic autobiographical memory (EAM) and self-representations (QSR) results

326 Considering the significant difference between both groups on state anxiety scores $(p=0.01)$

327 and the possible effect of state anxiety on EAM and self-representations scores, the two

328 groups were divided in two subgroups on the basis of their state anxiety median (see 2.6

329 Statistical analyses). Factorial ANOVAs with the factors Group (patients, controls) and

330 Anxiety (the least anxious, the most anxious) on EAM and QSR scores show the effects of

331 illness and anxiety, and interactions between these two factors. Results of these analyses are 332 presented in Table 2.

333 Concerning the EAM scores per life time period, the factorial ANOVA revealed a significant

334 effect of group for the reminiscence bump only $[F(1,76)=4.49 ; p=0.04]$, LSD post-hoc 335 showing that the most anxious patients retrieved significantly fewer details for the 336 reminiscence bump period than the least anxious controls $(p=0.04)$.

337 Concerning the EAM scores for specific details, a main effect of group was observed for the 338 emotional details only $[F(1,76)=6.33 ; p=0.01]$, and no other main effect or interaction was 339 revealed. The most anxious patients retrieved significantly fewer emotional details than the 340 most anxious controls $(p=0.03)$ and the least anxious controls $(p=.03)$ (see Figure 2).

341 Emotional ratings of memories were also analysed. Concerning Valence at encoding, a main 342 effect of group was observed $[F(1,76)=5.11 ; p=0.03]$ and the interaction group $\mathrm{x}$ anxiety 343 tends to be significant $[F(1,76)=3.36 ; p=0.07]$ : the most anxious patients judged their 344 memories at encoding significantly more positively and more pleasant than the most anxious 
345 and the least anxious controls ( $p=0.006$ and $p=0.049$, respectively). No significant effects 346 were observed for Valence at retrieval. Concerning Intensity at encoding and Intensity at 347 retrieval, effects of group were or tended to be significant [at encoding: $F(, 176)=3.71 ; p=$ 348 0.06; at retrieval: $F(1,76)=4.56 ; p=0.04$ ], as well as interactions group $\mathrm{x}$ anxiety [at 349 encoding: $F(1,76)=3.40, p=0.07$; at retrieval: $F(1,76)=6.76, p=0.01$ ]: the least anxious 350 patients rated their memories at encoding and at retrieval as less emotionally intense than the 351 most anxious patients $(p=0.07$ and $p=0.02)$, the most anxious controls $(p=0.04$ and $\mathrm{p}=$ 352 0.02), and the least anxious controls ( $p=0.008$ and $p=0.001)$ (see Figure 3). Furthermore, in 353 each subgroup, significant Spearman correlations were observed between ratings of emotions 354 (valence or intensity) experienced at encoding and retrieval, except for intensity in the most 355 anxious patients (the most anxious patients: $p=0.08$ for intensity and $p=0.02$ for valence; 356 the least anxious patients: $p=0.004$ for intensity and $p=0.02$ for valence; the most anxious controls: $p<0.0001$ for intensity and $p=0.001$ for valence; the least anxious controls: $p$ s $<$ 3580.0001 for intensity and valence).

359 Concerning self-representation scores (QSR scores), no significant effect was reported for 360 validity scores. On the contrary, for certainty scores, we observed only a significant effect of 361 anxiety $[F(1,76)=12.28, p=0.0008]$ : the least anxious patients had higher certainty scores 362 than the most anxious patients $(p=0.009)$ and the most anxious control $(p=0.0004)$; and the 363 least anxious controls had higher certainty scores than the most anxious controls $(p=0.03)$. 364 For valence scores, we reported a main effect of group $[F(1,76)=5.42, p=0.02]$ and a main 365 effect of anxiety $[F(1,76)=16.94, p<0.0001]$ : the least anxious patients obtained higher 366 valence scores (i.e. more positive) than the most anxious patients $(p=0.01)$ and the most 367 anxious controls $(p<0.0001)$; and the least anxious controls had higher valence scores than the most anxious controls $(p=0.001)$. These main effects of anxiety are in line with the 
significant negative correlations between QRS scores (certainty or valence) and state anxiety

370 scores in the whole patient group $(p<0.006)$ and in the whole control group $(p<0.008)$.

\section{DISCUSSION}

373 This study is the first to focus on autobiographical memory functioning in patients newly 374 diagnosed for breast cancer, before receiving any adjuvant treatment. Previously, only a 375 handful of studies reported impaired retrieval of specific autobiographical memories in 376 patients with breast cancer in remission (i.e., these patients had received neurotoxic treatments 377 like chemotherapy and/or hormonotherapy; Nilsson-Ihrfelt et al. 2004; Bergouignan et al. 378 2011). Here, we aimed at determining what triggers and causes the impairment of EAM 379 independently of the impact of adjuvant treatments. State anxiety related to breast cancer 380 diagnosis typically peaks in the period between breast cancer diagnosis and adjuvant 381 treatment (e.g., Schnur et al. 2008; Montgomery \& McCrone, 2010; Galloway et al. 2012; 382 Berman et al. 2013; Groarke et al. 2013). Consistently, we found a significantly higher level 383 of state anxiety, but no difference in trait anxiety or in depressive symptoms, in the patients 384 with breast cancer compared with healthy women with no history of cancer.

385 The impact of state anxiety was specifically explored here, dividing the patient group and the control group on the basis of state anxiety (STAI) median into "the least anxious" and "the

387 most anxious" subjects. The main result reveals that the most anxious patients seem to be 388 impaired in their EAM retrieval, as they reported significantly less emotional details than 389 controls, whereas the least anxious patients showed a profile of EAM retrieval similar to those 390 of controls.

391 This result reveals two profiles of emotional processing during autobiographical memory 392 retrieval among patients who have experienced cumulative stressful events. Although the least 393 and the most anxious patients have lived the same stressful events related to cancer diagnosis 
and surgery, they showed different EAM patterns. The hypotheses on the impact of

395 cumulative stressful events after breast cancer diagnosis and surgery on cognition (Berman et al. 2013), and more specifically on EAM (Bergouignan et al. 2011), might therefore be modulated by the psychological reaction (state anxiety level) of patients.

398 Furthermore, although the most anxious patients retrieved fewer emotional details than 399 controls, we cannot characterise this abnormality as overgeneral memories because, for each 400 memory retrieved, the event-specific knowledge level was reached. This pattern of results for 401 the most anxious patients may therefore not be attributable to executive dysfunctions (that are 402 inexistent in patients). On the contrary, since on one hand, the generative retrieval process 403 depends on the working self (Conway et al. 2004), and on the other hand, our results 404 demonstrated that state anxiety scores and QSR scores correlated, we suggest that this 405 particular pattern of EAM is influenced by self-representations. Indeed, immediately after 406 retrieval, participants rated emotions they had experienced when the event originally took 407 place (i.e., at encoding) and those they experienced when they related that event to the 408 experimenter (i.e., at retrieval) on two emotional scales evaluating valence and intensity. 409 Remarkably, in each subgroup, significant correlations were observed between ratings of 410 emotions (valence or intensity) experienced at the time of encoding and retrieval, except for 411 intensity in the most anxious patients. This may suggest modified self-representations for 412 these patients: their current concern may fade the intensity of the past events. Moreover, 413 compared with controls (least and most anxious subgroups), the most anxious patients rated 414 their memories as more pleasant (higher positive emotional valence ratings) at encoding, but 415 no differences were observed for retrieval. These patients were therefore able to retrieve 416 positive personal past events, but reduced the emotional verbalization of their memories. It is 417 worth noting that, in the TEMPau task, memories and their specific details (factual, spatial, 418 temporal and emotional) were given spontaneously, with no prompting provided by the 
experimenter, and no restrictions placed on the emotional valence of these memories. These

420 findings may suggest that the most anxious patients appear to engage in an avoidance strategy

421 to diminish the emotional impact of recalling strongly negative events from the past, thus

422 enabling them to cope more effectively with the disease. This strategy could be close to the

423 hypothesis that reduced memory specificity may be a coping strategy of cognitive avoidance

424 used under certain conditions by individuals without psychiatric diagnosis (Hermans et al.

425 2008; Deeber et al. 2012). We can suggest that a coping strategy that allows a higher

426 appreciation of past events although entertaining anxiety during the present moment

427 encourages the impulse to recover past health conditions. Significant differences between

428 groups were observed for state anxiety scores, but not for trait anxiety scores, suggesting that

429 anxious preoccupation may indeed be a psychological consequence of the breast cancer

430 diagnosis experience, and may play an important role in coping with the disease and adhering

431 to chemotherapy (Greer et al. 2008; Watson et al. 2012; Groarke et al. 2013).

432 By contrast, our results revealed that, after breast cancer diagnosis and despite the context of a

433 life-threating disease, some patients exhibited a combination of low state anxiety scores and

434 high self-representation scores. Unlike the most anxious patients, these patients did not

435 exhibit any deficit in the specificity of emotional detail in EAM retrieval compared with

436 healthy controls. Results of the emotional ratings showed that the least anxious patients

437 judged their memories to be less intense (less emotionally charged), both at encoding and at

438 retrieval, compared with the most anxious patients and the controls (the least or the most

439 anxious controls). The least anxious patients had also higher self-representation scores

440 (certainty and valence) than the most anxious patients and the most anxious controls. To

441 categorize events as less intense, although possibly being a judgment bias, may reinforce

442 confidence in the ability to cope with stressful events and then reinforce self-esteem. So, this

443 subgroup of less anxious patients exhibited stable EAM including emotional details, but rated 
444 their memories as being less emotionally intense than the three other subgroups, notably the

445 least anxious controls. These results may lend support to the theory that autobiographical 446 memory is closely and reciprocally linked to self-representation (Conway, 2005; Klein \&

447 Gangi, 2010; Haslam et al. 2011). This profile may reflect the adoption of another adaptive 448 process in order to cope with the stressful events related to breast cancer diagnosis (i.e., 449 coping strategies). The least anxious patients are able to deal with, regulate and express their 450 emotions.

451 We can hypothesize that patients implement emotion-focused coping strategies, to control the 452 emotions triggered during the stressful period of breast cancer diagnosis, thereby achieving an 453 affective and emotional balance (Khalili et al. 2013), or assertive coping strategies, related to 454 higher self-representation scores (certainty and valence) (Astin et al. 1999). The patients took 455 part in a lengthy research study over three sessions with cognitive, EAM and psychosocial 456 assessments, as well as neuroimaging exams, on three occasions (before adjuvant treatment, 457 after treatment, and one year later). This suggests that the patients included in this study had 458 to be highly self-willed. In this context, our results could be interpreted as indicative of a 459 positive temperament and/or the ability to engage in an adaptive process to cope with the 460 disease. To test this hypothesis, other studies will be needed to prospectively assess patients 461 who have a positive mammogram finding before and after any breast cancer diagnosis. 462 Interviews with immediate family members (children or partners) to obtain descriptions of the 463 patients before and after the breast cancer diagnosis experience might also be interesting.

\section{5. Conclusions and Perspectives}

466 We were able to identify two patient profiles for emotional processing in autobiographical 467 memory retrieval. Compared with healthy women with no history of cancer, the most anxious 468 patients exhibited impaired EAM retrieval, particularly regarding the specificity of emotional 
469 details. Another, less expected profile involved the least anxious patients with higher self470 representation scores, who did not exhibit any deficit in emotional detail retrieval in EAM. 471 More research is needed to confirm these profiles and provide advice regarding the 472 psychological impact on cognition among patients and oncologists. Other avenues for 473 research might include investigating EAM, state anxiety, and self-representation profiles after 474 chemotherapy, in order to find out whether or not the changes observed during the breast 475 cancer diagnosis experience are temporary. One might suggest that therapeutic methods for 476 decreasing state anxiety could minimize memory dysfunctions and more largely cognitive 477 deficits.

478 


\section{Financial support}

480 This work was supported by "Canceropôle Nord-Ouest", the French charities "Ligue contre le 481 cancer" and "Le cancer du sein, parlons-en!" (Pink Ribbon), and the French Ministry of 482 Higher Education and Research.

\section{Acknowledgments}

485 The authors would like to thank Aurélie Daireaux, Chantal Rieux, and the oncologists of the 486 medical oncology department of the Centre François Baclesse (Caen) (Dr Delcambre, Dr 487 Ollivier, Dr Berthet, Dr Segura and Dr Swisters) for their help in patient recruitment. The 488 authors would like to thank Fanny Pottier, Céline Graule, Caroline Baylac and Aurélia Siroit 489 for their help with the data acquisition, the patients and volunteers for taking part in this study 490 and Elisabeth Portier for reviewing the English style. Finally, the authors are grateful to Dr 491 Mickaël Laisney, Dr Laurence Picard and Dr Céline Duval for their help in various stages of 492 this study and their precious comments and support. 
Abdollahi M, Moradi A, Hasani J, \& Jobson L (2012). Investigating the relationships between autobiographical remembering, the self and posttraumatic stress disorder in individuals with HIV, Memory 20, 872-881.

Ahles TA, Saykin AJ, McDonald BC, Furstenberg CT, Cole BF, Hanscom BS, Mulrooney TJ, Schwartz GN, \& Kaufman PA (2008). Cognitive function in breast cancer patients prior to adjuvant treatment, Breast cancer research and treatment 110, 143-152.

Andersson G, Hesser H, Cima RF, \& Weise C (2013). Autobiographical memory specificity in patients with tinnitus versus patients with depression and normal controls, Cognitive Behaviour Therapy 42, 116-126.

Astin JA, Anton-Culver H, Schwartz CE, Shapiro DH Jr, McQuade J, Breuer AM, Taylor TH, Lee H, \& Kurosaki T (1999). Sense of control and adjustment to breast cancer: the importance of balancing control coping styles, Behavioral medicine (Washington, D.C.) 25, 101-109.

509 Baize N, Mounier N, Bongain A, \& Spano J-P (2008). [Femininity and breast cancer, original approach of announcement in oncology], Bulletin du cancer 95, 849-857.

511 Beck AT, Ward CH, Mendelson M, Mock J, \& Erbaugh J (1961). An inventory for measuring depression, Archives of general psychiatry 4, 561-571. cancer affects both the hippocampus volume and the episodic autobiographical memory retrieval, PloS one 6, e25349.

516 Berman MG, Askren MK, Sook Jung M, Therrien B, Peltier S, Noll DC, Zhang M, 517 Ossher L, Hayes DF, Reuter-Lorenz PA, \& Cimprich B (2013). Pretreatment Worry and 518 Neurocognitive Responses in Women With Breast Cancer, Health psychology: official 519 journal of the Division of Health Psychology, American Psychological Association

520 Brewin CR, Watson M, McCarthy S, Hyman P, \& Dayson D (1998). Intrusive memories 521 and depression in cancer patients, Behaviour Research and Therapy 36, 1131-1142.

522 Brickenkamp R, \& Zillmer E (1998). The d2 test of attention. Hogrefe \& Huber Pub.

523 Campbell JD, Trapnell PD, Heine SJ, Katz IM, Lavallee LF, \& Lehman DR (1996). Self524 concept clarity: Measurement, personality correlates, and cultural boundaries, Journal of 525 Personality and Social Psychology 70, 141-156.

Cardebat D, Doyon B, Puel M, Goulet P, \& Joanette Y (1990). Evocation lexicale formelle et sémantique chez des sujets normaux. Performances et dynamiques de production en fonction du sexe, de l'âge et du niveau d'étude, Acta Neurologica Belgica 90, 207-217.

Caron R, Leroy F, Berl S, \& Beaune D (2007). L'impossible écart entre représentations du corps malade et représentation de soi, Psycho-Oncologie 1, 41-47.

531 Carver CS, Smith RG, Antoni MH, Petronis VM, Weiss S, \& Derhagopian RP (2005).

532 Optimistic personality and psychosocial well-being during treatment predict psychosocial 
well-being among long-term survivors of breast cancer, Health psychology: official journal of the Division of Health Psychology, American Psychological Association 24, 508-516.

Chetelat G, Desgranges B, de la Sayette V, Viader F, Berkouk K, Landeau B, Lalevée C, Le Doze F, Dupuy B, Hannequin D, Baron J-C, \& Eustache F (2003). Dissociating atrophy and hypometabolism impact on episodic memory in mild cognitive impairment, Brain: a journal of neurology 126, 1955-1967.

Cimprich B, Reuter-Lorenz P, Nelson J, Clark PM, Therrien B, Normolle D, Berman MG, Hayes DF, Noll DC, Peltier S, \& Welsh RC (2010). Prechemotherapy alterations in brain function in women with breast cancer, Journal of Clinical and Experimental Neuropsychology 32, 324-331.

Conway MA (2005). Memory and the self, Journal of Memory and Language 53, 594-628.

Conway MA, \& Pleydell-Pearce CW (2000). The construction of autobiographical memories in the self-memory system, Psychological Review 107, 261-288.

Conway MA, Singer JA, \& Tagini A (2004). The self and autobiographical memory: correspondence and coherence, Social Cognition 22, 491-529.

Coopersmith S (1984). Inventaire d'estime de soi (S.E.I.). Paris: Les Editions du Centre de Psychologie Appliquée.

Debeer E, Raes F, Claes S, Vrieze E, Williams JM, \& Hermans D (2012). Relationship between cognitive avoidant coping and changes in overgeneral autobiographical memory retrieval following an acute stressor, Journal of Behavior Therapy and Experimental Psychiatry 43 Suppl 1, S37-42.

Duval C, Desgranges B, de La Sayette V, Belliard S, Eustache F, \& Piolino P (2012). What happens to personal identity when semantic knowledge degrades? A study of the self and autobiographical memory in semantic dementia, Neuropsychologia 50, 254-265.

Eustache F, Desgranges B, \& Lalevée C (1998). [Clinical evaluation of memory], Revue neurologique 154 Suppl 2, S18-32.

559 Fitts WH, \& Warren WL (1996). Tennessee self-concept scale: TSCS: 2. Western Psychological Services Los Angeles.

561 Fouquet M, Desgranges B, La Joie R, Rivière D, Mangin J-F, Landeau B, Mézenge F, Pélerin A, de La Sayette V, Viader F, Baron J-C, Eustache F, \& Chételat G (2012). Role of hippocampal CA1 atrophy in memory encoding deficits in amnestic Mild Cognitive Impairment, NeuroImage 59, 3309-3315.

Galloway SK, Baker M, Giglio P, Chin S, Madan A, Malcolm R, Serber ER, Wedin S,

566 Balliet W, \& Borckardt J (2012). Depression and Anxiety Symptoms Relate to Distinct 567 Components of Pain Experience among Patients with Breast Cancer, Pain research and 568 treatment 2012, 851276.

569 Giffard B, Viard A, Dayan J, Morel N, Joly F, \& Eustache F (2013). Autobiographical 570 Memory, Self, and Stress-Related Psychiatric Disorders: Which Implications in Cancer 571 Patients?, Neuropsychology Review 23, 157-168. 
Greer JA, Pirl WF, Park ER, Lynch TJ, \& Temel JS (2008). Behavioral and psychological predictors of chemotherapy adherence in patients with advanced non-small cell lung cancer, Journal of Psychosomatic Research 65, 549-552.

Groarke A, Curtis R, \& Kerin M (2013). Global stress predicts both positive and negative emotional adjustment at diagnosis and post-surgery in women with breast cancer, Psychooncology 22, 177-185.

Haque S, Juliana E, Khan R, \& Hasking P (2014). Autobiographical memory and hierarchical search strategies in depressed and non-depressed participants, BMC Psychiatry 14,310 .

Haslam C, Jetten J, Haslam SA, Pugliese C, \& Tonks J (2011). "I remember therefore I am, and I am therefore I remember": exploring the contributions of episodic and semantic self-knowledge to strength of identity, British journal of psychology (London, England: 1953) 102, 184-203.

Hermans D, de Decker A, de Peuter S, Raes F, Eelen P, \& Williams JMG (2008). Autobiographical memory specificity and affect regulation: coping with a negative life event, Depression and Anxiety 25, 787e792.

Joly F, Rigal O, Noal S, \& Giffard B (2011). Cognitive dysfunction and cancer: which consequences in terms of disease management? Psycho-Oncology 20, 1251-1258.

590 La Joie R, Landeau B, Perrotin A, Bejanin A, Egret S, Pélerin A, Mézenge F, Belliard S, 591 de La Sayette V, Eustache F, Desgranges B, \& Chételat G (2014). Intrinsic Connectivity 592 Identifies the Hippocampus as a Main Crossroad between Alzheimer's and Semantic 593 Dementia-Targeted Networks, Neuron 81, 1417-1428.

594 Kalafat M, Hugonot-Diener L, \& Poitrenaud J (2003). Standardisation et étalonnage 595 français du "Mini Mental State"(MMS) version GRECO, Revue de neuropsychologie 13, 596 209-236.

Kangas M, Henry JL, \& Bryant RA (2005). A prospective study of autobiographical memory and posttraumatic stress disorder following cancer, Journal of Consulting and Clinical Psychology 73, 293-299. of life and pain in women with breast cancer, Iranian Journal of Nursing and Midwifery Research 18, 105.

603 Klein SB, \& Gangi CE (2010). The multiplicity of self: neuropsychological evidence and its implications for the self as a construct in psychological research, Annals of the New York 605 Academy of Sciences 1191, 1-15.

606 Klein SB, \& Lax ML (2010). The unanticipated resilience of trait self-knowledge in the face 607 of neural damage Memory 18, 918-948. 
Liu X, Liu Y, Li L, Hu Y, Wu S, \& Yao S (2014). Overgeneral autobiographical memory in patients with chronic pain, Pain Medicine 15, 432-439.

610 McGregor BA, \& Antoni MH (2009). Psychological intervention and health outcomes 611 among women treated for breast cancer: a review of stress pathways and biological mediators, 612 Brain, behavior, and immunity 23, 159-166.

613 Montgomery M, \& McCrone SH (2010). Psychological distress associated with the 614 diagnostic phase for suspected breast cancer: systematic review, Journal of advanced nursing 615 66, 2372-2390.

616 Moore SA, \& Zoellner LA (2007). Overgeneral autobiographical memory and traumatic events: an evaluative review, Psychological Bulletin 133, 419-437.

Nilsson-Ihrfelt E, Fjällskog M-L, Liss A, Jakobsson O, Blomqvist C, \& Andersson G (2004). Autobiographical memories in patients treated for breast cancer, Journal of

$620 \quad$ Psychosomatic Research 57, 363-366.

621 Piolino P, Desgranges B, Belliard S, Matuszewski V, Lalevée C, de La Sayette V, et al. 622 (2003). Autobiographical memory and autonoetic consciousness: triple dissociation in 623 neurodegenerative diseases, Brain 126, 2203-2219.

624 Piolino P, Desgranges B, Benali K, \& Eustache F (2002). Episodic and semantic remote 625 autobiographical memory in ageing, Memory 10, 239-257.

626 Piolino P, Desgranges B, \& Eustache F (2009). Episodic autobiographical memories over the course of time: cognitive, neuropsychological and neuroimaging findings,

628 Neuropsychologia 47, 2314-2329.

629 Piolino P, Hisland M, Ruffeveille I, Matuszewski V, Jambaqué I, \& Eustache F (2007). 630 Do school-age children remember or know the personal past?, Consciousness and Cognition 631 16, 84-101.

632 Przezdziecki A, Sherman KA, Baillie A, Taylor A, Foley E, \& Stalgis-Bilinski K (2013). 633 My changed body: breast cancer, body image, distress and self-compassion, Psycho-oncology $634 \quad 22,1872-1879$.

635 Pucheu S (2004). La guérison psychique du cancer ou le retour à l'harmonie du «moi », 636 Revue Francophone de Psycho-Oncologie 3, 61-64.

637 Quesnel C, Savard J, \& Ivers H (2009). Cognitive impairments associated with breast 638 cancer treatments: results from a longitudinal study, Breast Cancer Research and Treatment 639 116, 113-123.

640 Reitan RM (1992). Trail Making Test: Manual for administration and scoring. Reitan 641 Neuropsychology Laboratory.

642 Scheier MF, \& Carver CS (1985). The Self-Consciousness Scale: A Revised Version for 643 Use with General Populations1, Journal of Applied Social Psychology 15, 687-699. 
648 Spielberger CD, Gorsuch RL, \& Lushene RE (1970). Manual for the State-Trait Anxiety 649 Inventory

650 Stokes R, \& Frederick-Recascino C (2003). Women's perceived body image: relations with 651 personal happiness, Journal of women \& aging 15, 17-29.

652 St Jacques PL, Kragel PA, \& Rubin DC (2013). Neural networks supporting 653 autobiographical memory retrieval in posttraumatic stress disorder, Cognitive, Affective and 654 Behavioral Neuroscience 13, 554-566.

655 Sumner JA (2012). The mechanisms underlying overgeneral autobiographical memory: an 656 evaluative review of evidence for the CaR-FA-X model, Clinical Psychology Review 32, 3465748.

658 Sumner JA, Griffith JW, \& Mineka S (2010). Overgeneral autobiographical memory as a 659 predictor of the course of depression: a meta-analysis, Behaviour Research and Therapy 48, $660 \quad 614-625$.

661 Tulving E (2002). Episodic memory: from mind to brain, Annual review of psychology 53, 166225.

663 Watson M, Homewood J, \& Haviland J (2012). Coping response and survival in breast 664 cancer patients: a new analysis, Stress and health: journal of the International Society for the 665 Investigation of Stress 28, 376-380.

666 Wechsler D (2008). Echelle d'intelligence de Wechsler pour adultes: eWAIS-III. Les Editions 667 du Centre de Psychologie Appliquée.

668 Wefel JS, Saleeba AK, Buzdar AU, \& Meyers CA (2010). Acute and late onset cognitive 669 dysfunction associated with chemotherapy in women with breast cancer, Cancer 116, 33486703356.

671 Wefel JS, \& Schagen SB (2012). Chemotherapy-related cognitive dysfunction, Current 672 neurology and neuroscience reports 12, 267-275.

673 Williams JM, \& Broadbent K (1986). Autobiographical memory in suicide attempters, 674 Journal of abnormal psychology 95, 144.

675 Williams AD, \& Moulds ML (2007). An investigation of the cognitive and experiential 676 features of intrusive memories in depression, Memory 15, 912-920. 